\title{
Evaluation of bone alterations in the jaws of HIV-infected menopausal women
}

Bruno Vieira Caputo(a) Gabriela Cineze TraversaCaputo $^{(b)}$

Claudio Costa(c)

Elcio Magdalena Giovani ${ }^{(a)}$

(a) Center for Study and Care of Special Patients - CEAPE, Dental School, Univ Paulista - Unip, São Paulo, SP, Brazil.

(b) Private practice, São Paulo, SP, Brazil.

(c) Stomatology Department, Dental School, Univ de São Paulo, São Paulo, SP, Brazil.

Declaration of Interests: The authors certify that they have no commercial or associative interest that represents a conflict of interest in connection with the manuscript.

Corresponding Author:

Bruno Vieira Caputo

E-mail: bruvc@globo.com

Submitted: Sep 27, 2012

Accepted for publication: Feb 05, 2013

Last revision: Feb 14, 2013

\begin{abstract}
The advent of highly active antiretroviral therapy (HAART) has caused a reduction in mortality, thus contributing to an increase in the number of women with HIV/AIDS who reach the climacteric period, experience decline in ovarian function, and develop complications of viral infection and HAART, which can accelerate bone loss. The aim of this study was to detect possible alterations in the jaws of HIV-infected women by panoramic radiography. The study comprised a total of 120 women above 40 years of age who were divided into the following two groups: women who are HIV positive (Group I) and women with no known HIV infection (Group II). Measurement of the following three radiomorphometric indexes was performed by panoramic radiography: Mental Index (MI), Panoramic Mandibular Index (PMI) and Antegonial Depth (AD). A total of $70 \%$ of women in the control group and $50 \%$ of women in the HIV group were in the postmenopausal period, and the average values of both MI ( $p=0.0054)$ and AD $(p<0.0001)$ for this period were lower in the HIV group than in the control group. For patients who were in the premenopausal period, the average AD was lower in the HIV group than in the control group $(\mathrm{p}=0.0003)$. Despite the difference in the average age between groups, greater bone resorption in the mandible was found in the group of HIV-positive women.
\end{abstract}

Descriptors: HIV; Menopause; Radiography, Panoramic; Bone Resorption.

\section{Introduction}

The incidence of human immunodeficiency virus (HIV) infection is increasing among women. Over the years, the gender ratio for HIV infection has decreased gradually, and in recent years, there has also been an increase in the percentage of cases in the population over 40 years. A trend toward increased numbers of women with HIV has been observed in Brazil, and there has been an increased incidence of HIV infection among socioeconomically vulnerable populations. ${ }^{1}$

The advent of highly active antiretroviral therapy (HAART) has contributed to a significant increase in the life expectancy of these patients, thus providing these women with an opportunity to reach the climacteric stage. At this stage, these women experience a decline in ovarian function and may develop complications related to both HIV and HAART. ${ }^{2}$

The menopausal period is divided into the following three phases: 
Premenopause begins with the decline of ovarian function, and then the phase transition (i.e., perimenopause) occurs, which is followed by menopause. Postmenopause is the period after the cessation of ovarian function, which causes a reduction in estrogen and progestin levels. ${ }^{2,3}$

Women tend to experience a loss of bone mass at an accelerated rate after menopause; however, this demineralization in HIV-infected patients can be attributed to an important group of drugs known as antiretroviral protease inhibitors, which are known osteopenic agents. These drugs may increase the risk of bone fractures in people with HIV/AIDS. ${ }^{4-6}$

The factors that may contribute to the reduction in bone density in HIV-infected women include menstrual dysfunction (hormonal imbalance), weight loss (alterations in nutritional status), decreased body mass, increased bone resorption, and Caucasian ethnicity. These risk factors are associated with an increase in the incidence of osteopenia and osteoporosis. $^{7}$

Bone densitometry is considered the gold standard among imaging methods used for disease diagnosis. ${ }^{8}{ }^{8}$ However, the cost and lack of access to this exam both hinder its use as a method for diagnosing the pathology. Considering this difficulty, researchers have been seeking new ways to assist in the early diagnosis of osteoporosis. Studies have shown a correlation between radiomorphometric indexes in dental radiographs and the bone mineral density of the lumbar spine, femoral neck and jaw. ${ }^{10-13}$

Panoramic radiography is a low-cost exam that is routinely performed in dental clinics, and a large number of tests are performed annually to aid in the diagnosis of oral pathologies, such as dental caries. Hence, it would be beneficial if radiographs could be used to identify menopausal women with undetected osteoporosis. Dentists could evaluate the mandibular alveolar ridge and make necessary referrals for patients who require a more specific diagnosis and treatment. ${ }^{14,15}$

The erosion in the lower jaw cortex, which is detected on panoramic radiographs, may be an important indicator for identifying older individuals or postmenopausal women with low bone mineral density. ${ }^{15-17}$ Because of the possible alterations in bone structure of the jaws in general and especially in HIV patients who are being treated with HAART, our aim was to identify these bone alterations in women with HIV who are 40 years of age or older and are experiencing pre-, peri- or postmenopause.

\section{Methodology}

A randomized cross-sectional study of HIVpositive menopausal women who were undergoing dental care was conducted by surveying data on the signs, symptoms, and characteristics of menopause and performing an analysis of panoramic radiography. The study was approved by the Ethics Committee of Paulista University (220/10).

A total of 120 women were included in the study; they were divided into the following two groups:

- Group I: Sixty women were selected from among those referred to the Center for Study and Care of Special Patients (CEAPE) at Paulista University in Brazil from June 2010 to February 2011. The inclusion criteria for this group were as follows:

- 40 years of age or older,

- experiencing at least three symptoms of menopause,

- HIV-positive status (ELISA/Western blot), and - using HAART.

- Group II (control group): This group included 60 women who attended the Integrated Clinic at Paulista University in Brazil from June 2010 to February 2011 and were not HIV-positive. Inclusion criteria, which were similar to those in the other group, were as follows:

- 40 years of age or older and

- experiencing at least three symptoms of menopause.

The patients were classified based on the period of menopause according to the presence or absence of bleeding, as in the study by Ferreira et al. ${ }^{2}$

Panoramic radiography was performed using a Rotograph Plus ${ }^{\circledR}$ X-ray machine (Villa Medical System, Buccinasco, Italy) with an exposure time of 16 seconds and an average increase of $25 \%$ under a working milliamperage of $10 \mathrm{~mA}$ and a kilovoltage 


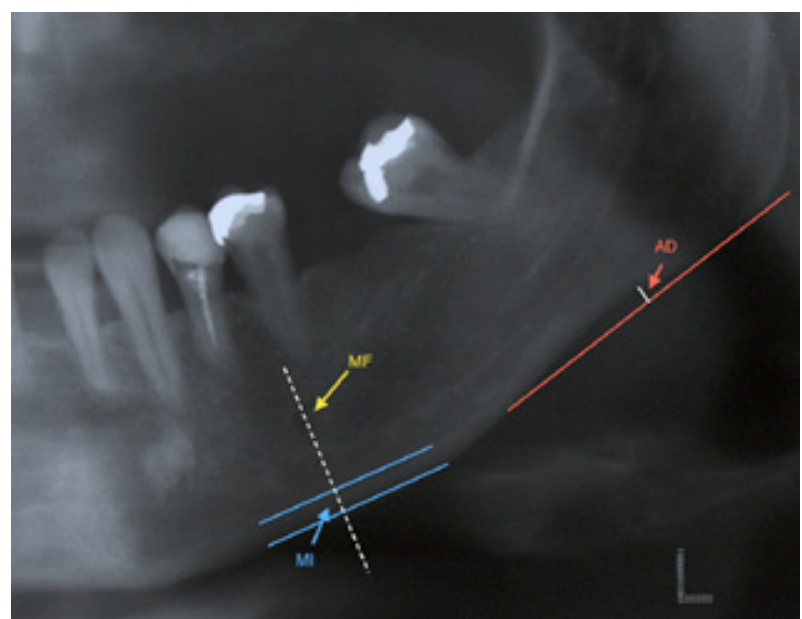

Figure 1 - A cropped panoramic radiograph showing the $\mathrm{MI}$ and $\mathrm{AD}$ measurements.

of $70 \mathrm{kVp}$.

Subsequently, the subjects were scanned using a Scanner HP Scanjet G4050 ${ }^{\circledR}$ (Hewlett-Packard Development Company, L.P., Palo Alto, USA) in positive mode using the transparent materials adapter (TMA) at a resolution of $300 \mathrm{dpi}$ and $100 \%$ grayscale. The scanned image was downloaded and opened in Image ${ }^{\circledR}$ software, version 1.44 for Mac OS X operating system (Public domain image processing program, National Institutes of Health, Bethesda, USA), in which readings of the entire bone structure were taken, particularly of the trabecular bone, to observe bone integrity (or the loss thereof) and possible resorption at the points of interest. The following linear measurements were also performed:

- The Mental Index (MI $)^{17}$ is the marking of the route that parallels the lower border of the mandible and is perpendicular from the center of the mental foramen (MF) to the cortical lower jaw. This index measures the height of the mandibular inferior cortex (the normal value is greater than or equal to $3.1 \mathrm{~mm}$ ) (Figure 1).

- Antegonial Depth $(\mathrm{AD})^{18}$ measures the distance along the perpendicular line from the deepest point of the concave antegonial notch depth to the lower cortical line that is parallel to the edge of the mandible (Figure 1).

- The Panoramic Mandibular Index (PMI ${ }^{19}$ is the ratio of the mandibular cortical thickness as measured on a line that is perpendicular to the

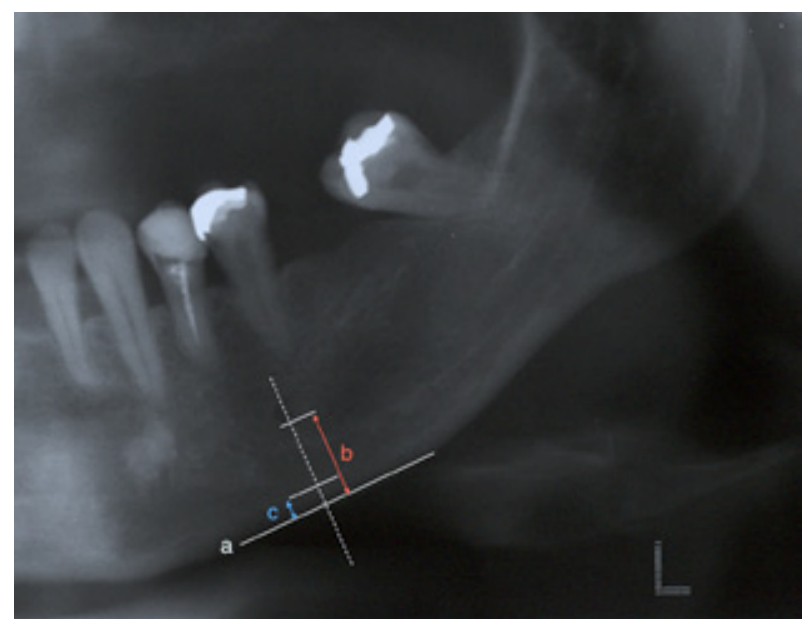

Figure 2 - A cropped panoramic radiograph showing the $\mathrm{PMI}$ measurements (c/b). Lines a (parallel to the lower border of the mandible), $b$ (distance between the bottom of the mental foramen and the base of the mandible, and c (cortical thickness).

base of the mandible, the height of the center of the mental foramen, the distance between the bottom of the mental foramen and the base of the mandible (the normal value is greater than or equal to $0.3 \mathrm{~mm}$ ) (Figure 2).

Measurements were obtained in millimeters bilaterally. Panoramic radiographs were randomly selected from a sample to collect measurements, and a blind observer made these measurements for each group. The data were statistically analyzed such that the quantitative variables were compared between groups using Student's t-test. For the qualitative variables, we used the chi-square test of traditional homogeneity. In addition, group comparisons were performed in terms of the radiomorphometric degree indexes using the Mann-Whitney test to confirm the results. For variables with only two levels, we used Fisher's exact test, and for the other variables, we used the chi-square test. For all of the tests, the significance level was 5\%.

There was intraexaminer agreement for the measurements that were repeated 14 days after the initial measurements, and the results were compared with the first measurements.

\section{Results}

There was a significant difference in the mean 
Table 1 - Prevalence (\%) of menopausal symptoms according to the characteristics of the studied population.

\begin{tabular}{|c|c|c|c|c|c|}
\hline \multirow{2}{*}{ Characteristics } & \multicolumn{2}{|c|}{ Group I } & \multicolumn{2}{|c|}{ Group II (control) } & \multirow{2}{*}{$p$} \\
\hline & $\mathrm{n}$ & $\%$ & $\mathrm{n}$ & $\%$ & \\
\hline \multicolumn{6}{|c|}{ Menopause classification } \\
\hline Premenopause & 8 & 13.3 & 10 & 16.7 & \multirow{3}{*}{0.0126} \\
\hline Perimenopause & 22 & 36.7 & 8 & 13.3 & \\
\hline Postmenopause & 30 & 50 & 42 & 70 & \\
\hline \multicolumn{6}{|c|}{ Signs and symptoms of menopause } \\
\hline Psychological & 58 & 96.7 & 53 & 88.3 & 0.1629 \\
\hline Vasomotor & 48 & 80 & 48 & 80 & 1.0000 \\
\hline Insomnia & 44 & 73.3 & 40 & 66.7 & 0.4256 \\
\hline Genito-urinary & 43 & 71.7 & 42 & 70 & 0.8408 \\
\hline Palpitations & 24 & 40 & 24 & 40 & 1.0000 \\
\hline Weight gain & 21 & 35 & 20 & 33.3 & 0.8474 \\
\hline \multicolumn{6}{|c|}{ Hormonal therapy } \\
\hline Yes & 2 & 3.3 & 18 & 30 & \multirow{2}{*}{0.0001} \\
\hline No & 58 & 96.7 & 42 & 70 & \\
\hline \multicolumn{6}{|c|}{ Prevention of bone resorption } \\
\hline Vitamin D & 4 & 6.7 & 6 & 10 & 0.7430 \\
\hline Alendronate sodium & 4 & 6.7 & 12 & 20 & 0.0575 \\
\hline Calcium & 0 & 0 & 6 & 10 & 0.0274 \\
\hline Proper diet & 4 & 6.7 & 0 & 0 & 0.1187 \\
\hline None & 50 & 83.3 & 40 & 66.7 & 0.0350 \\
\hline
\end{tabular}

age of the patients between groups; the mean age of the patients in the control group was 56.1 years, and that of the patients in the HIV group was 46.9 years. Both groups were predominantly Caucasian (66.7\% of the control group and $60.0 \%$ of the HIV group). There was a predominance of postmenopausal women in both groups (Table 1). There was no significant difference in any of the signs and symptoms between groups $(\mathrm{p}>0.16)$.

The proportion of patients who were taking hormone replacement therapy was higher in the control group than in the HIV group $(\mathrm{p}=0.0001)$. In both groups, most of the women did not engage in any type of preventive practice for osteoporosis $(66.7 \%$ of women in the control group and $83.3 \%$ of women in the HIV group). In the control group, $20.0 \%$ of women were taking alendronate sodium, $10.0 \%$ of women were taking vitamin $\mathrm{D}$, and $10.0 \%$ of women were taking calcium.
Table 2 - Characteristics of women according to HIV status.

\begin{tabular}{l|c|c}
\hline \multirow{2}{*}{ Characteristics } & $n$ & $\%$ \\
\cline { 2 - 3 } & CD4 count $\left(\right.$ cells $\left./ \mathrm{mm}^{3}\right)$ \\
\hline $0-199$ & 12 & 20 \\
\hline $200-499$ & 22 & 36.7 \\
\hline$\geq 500$ & 26 & 43.3 \\
\hline \multicolumn{2}{|c}{ HIV status (number of copies) } \\
\hline Undetectable & 46 & 76.7 \\
\hline 0-50000 & 8 & 13.3 \\
\hline$>50000$ & 6 & 10 \\
\hline \multicolumn{2}{|c}{ HAART } & \\
\hline NRTI & 56 & 93.3 \\
\hline PI & 38 & 63.3 \\
\hline NNRTI & 20 & 33.3 \\
\hline II & 2 & 3.3 \\
\hline CCR5 receptor & 2.3 \\
\hline
\end{tabular}

Regarding the HIV patients, Table 2 shows the frequency distributions of the CD4 count, viral load, and HAART variables.

Table 3 shows the average results for the radiomorphometric index measures. Comparing the groups according to the stage of menopause, the $\mathrm{AD}$ was lower in the HIV group than in the control group $(p=0.0003)$ in the premenopausal period. In postmenopausal women, the values of both MI $(\mathrm{p}=0.0054)$ and $\mathrm{AD}(\mathrm{p}<0.0001)$ were lower in the HIV group (Figure 3 ) than in the control group (Figure 4).

\section{Discussion}

The results for the mean age and ethnicity were in accordance with those of another study conducted by Ferreira et al. ${ }^{2}$ in which the authors studied women with HIV and controls. According to Kojic et al., ${ }^{20}$ women with HIV present with early menopause (between 47 and 48 years of age), which explains the age discrepancies between the study group and the control group.

The decisions regarding the sample size accounted for the difficulty in identifying HIV-positive women who are at a more advanced age, need medical care and are willing to proceed with dental 
Table 3 - Mean, standard deviation and $p$ value of indexes (in $\mathrm{mm}$ ) in patients.

\begin{tabular}{|c|c|c|c|c|}
\hline Indexes & Group & Mean & SD & $p$ \\
\hline \multicolumn{5}{|c|}{ Premenopause } \\
\hline \multirow{2}{*}{ MI } & Control & 4.01 & 0.56 & \multirow{2}{*}{0.4349} \\
\hline & HIV & 3.86 & 0.12 & \\
\hline \multirow{2}{*}{ PMI } & Control & 0.36 & 0.06 & \multirow{2}{*}{0.8882} \\
\hline & HIV & 0.36 & 0.06 & \\
\hline \multirow{2}{*}{$A D$} & Control & 1.24 & 0.29 & \multirow{2}{*}{0.0003} \\
\hline & HIV & 0.68 & 0.20 & \\
\hline \multicolumn{5}{|c|}{ Perimenopause } \\
\hline \multirow{2}{*}{$\mathrm{MI}$} & Control & 4.06 & 0.45 & \multirow{2}{*}{0.8957} \\
\hline & HIV & 4.10 & 0.89 & \\
\hline \multirow[t]{2}{*}{ PMI } & Control & 0.33 & 0.05 & \multirow{2}{*}{0.9891} \\
\hline & HIV & 0.33 & 0.06 & \\
\hline \multirow{2}{*}{$A D$} & Control & 1.04 & 0.32 & \multirow{2}{*}{0.3049} \\
\hline & HIV & 1.26 & 0.58 & \\
\hline \multicolumn{5}{|c|}{ Postmenopause } \\
\hline \multirow{2}{*}{$\mathrm{Ml}$} & Control & 3.84 & 0.73 & \multirow{2}{*}{0.0054} \\
\hline & HIV & 3.36 & 0.63 & \\
\hline \multirow{2}{*}{ PMI } & Control & 0.33 & 0.07 & \multirow{2}{*}{0.1723} \\
\hline & HIV & 0.31 & 0.06 & \\
\hline \multirow{2}{*}{$A D$} & Control & 1.34 & 0.37 & \multirow{2}{*}{$<0.0001$} \\
\hline & HIV & 0.91 & 0.46 & \\
\hline
\end{tabular}

treatment. The division of the periods of menopause is in agreement with that used in previous studies. ${ }^{2}$

A considerable number of patients $(43.3 \%)$ had CD4 $\mathrm{T}$ counts that were equal to or greater than 500 cells $/ \mathrm{mm}^{3}$, while a slightly lesser number of patients $(36.7 \%)$ had CD4 T counts between 200 cells/ $\mathrm{mm}^{3}$ and 499 cells $/ \mathrm{mm}^{3}$. Regarding the viral load, most of the patients had undetectable loads $(76.7 \%)$, while $13.3 \%$ of the patients had a load of less than 50000 copies. The lower the cell counts of CD4 T lymphocytes circulating in the blood, the more immunocompromised the patient and the more likely it is that the patient may be affected by opportunistic infections, complications, and alterations in bone structure. These complications are likely to occur if the patient has a CD 4 count below 200 cells $/ \mathrm{mm}^{3}$, and the CD4 count is considered an important indicator for monitoring HIV patients in general. ${ }^{1}$

In both groups, menopausal symptoms were mostly psychological symptoms, followed by vasomotor symptoms; this finding is in agreement with the existing literature. ${ }^{2,21}$ Studies have shown that menopausal symptoms are common among HIV-infected women, even when they have not yet reached menopause. Several topics, such as the use of hormone replacement therapy by HIV-positive women, have not been discussed in the literature, but these topics have been studied in menopausal HIV-negative women. ${ }^{2,22}$ Some authors have emphasized that middle-aged women with HIV infection have reduced bone mineral density independent of the use of HAART and that the presence of osteopenia and osteoporosis cannot be attributed solely to the use of antiretroviral therapy. ${ }^{23,24}$

Several studies have shown that HAART may be associated with an increased prevalence of osteopenia and osteoporosis, which can increase the risk of bone fractures in people with HIV. Furthermore, protease inhibitors are known osteopenic agents; however, a more consistent link between this group of drugs and bone loss remains to be proven. . $-6,25-28^{-28}$

Panoramic radiography can be considered an auxiliary tool for dentists in the detection of possible alterations and bone fractures in the jaw, especially in postmenopausal women. ${ }^{13,14,29}$ Measurements of MI, PMI, and AD have already been used and have been validated in the scientific literature. ${ }^{10,17-19,29}$ In the postmenopausal subjects in this study, the values of both MI ( $\mathrm{p}=0.0054)$ and $\mathrm{AD}(\mathrm{p}<0.0001)$ were lower in the HIV group compared with those in the control group.

The mandibular cortical thickness below the mental foramen correlates with the mineral density of the lumbar spine and the proximal femur. A mandibular cortical thickness below the mental foramen of less than or equal to 3 millimeters could be considered a parameter for the diagnosis of low bone mineral density, and patients meeting this criterion could be referred for a bone densitometry examination. The authors also found that the low value of MI in postmenopausal women can be used to identify women with osteoporosis because this index is quantitative and has a moderate correlation with the BMD of the hip and lumbar regions, with high accuracy in intra and inter- 
Figure 3 - A panoramic radiograph of a 47-yearold HIV-infected postmenopausal woman with lower values of the indexes.

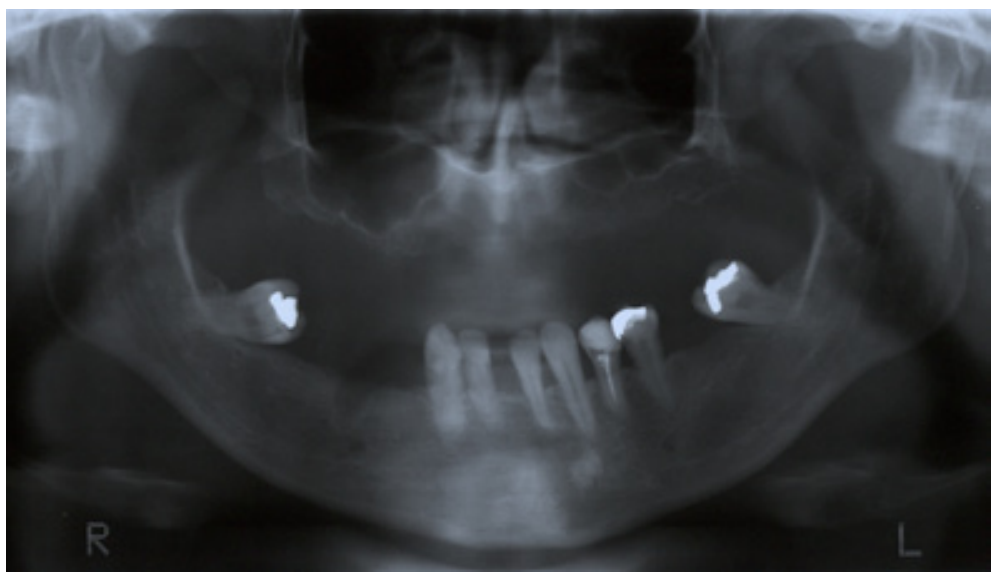

Figure 4 - A panoramic radiograph of a 57-yearold postmenopausal woman (control group) with higher values of the indexes.

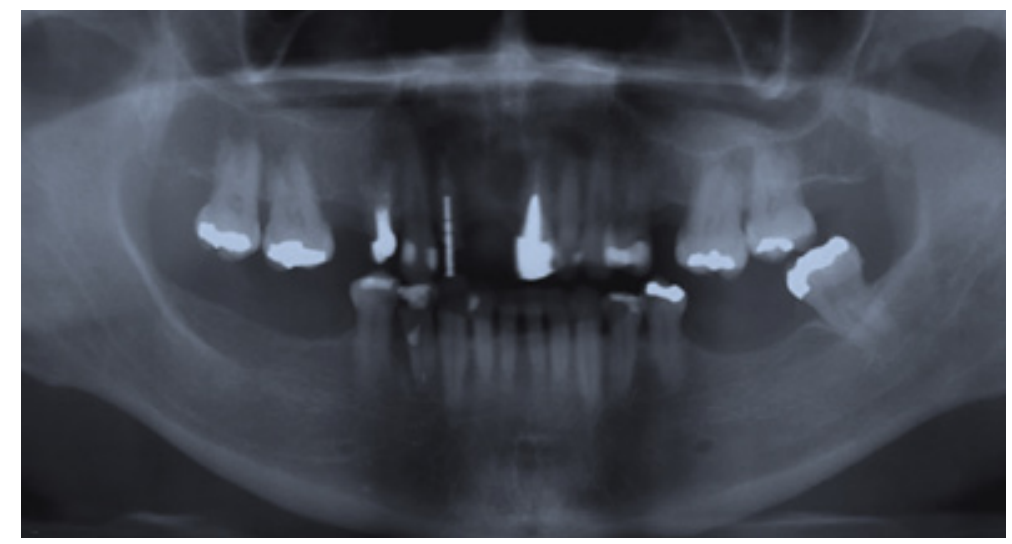

examination. ${ }^{10,12,17,29}$

Due to the lack of related studies involving HIV patients, we do not have sufficient data with which to compare our results for the radiomorphometric indexes of the HIV group, but other studies with HIV-negative patients have found a decrease in the AD. ${ }^{18,30}$ However, a recent study reported no significant differences in the mean $\mathrm{AD}$ or in the gonial angles compared to the bone mineral density values of the lumbar spine and hip. ${ }^{29}$

\section{Conclusion}

Panoramic radiography was demonstrated to be

\section{References}

1. Joint United Nations Program on HIV/AIDS. Report on the global HIV/AIDS epidemic 2008: executive summary. Geneva: UNAIDS; 2008. 36 p.

2. Ferreira CE, Pinto-Neto AM, Conde DM, Costa-Paiva L, Morais SS, Magalhães J. Menopause symptoms in women an efficient method for performing jaw measurements correlated to bone density. Despite the difference in the average age between groups, greater bone resorption in the mandible was found in the group of HIV-positive women. Further studies are required to identify and establish links between HIV-infected women, HAART, and menopause.

\section{Acknowledgements}

To Coordenação de Aperfeiçoamento de Pessoal de Nível Superior - Programa de Suporte à PósGraduação de Instituições de Ensino Particulares (CAPES-PROSUP). infected with HIV: prevalence and associated factors. Gynecol Endocrinol. 2007 Apr;23(4):198-205.

3. Paoletti R, Wenger NK. Review of the International Position Paper on Women's Health and Menopause: a comprehensive approach. Circulation. 2003 Mar 11;107(9):1336-9. 
4. Walker Harris V, Brown TT. Bone loss in the HIV-infected patient: evidence, clinical implications, and treatment strategies. J Infect Dis. 2012 Jun;205 Suppl 3:S391-8.

5. Pinto Neto LF, Ragi-Eis S, Vieira NF, Soprani M, Neves MB, Ribeiro-Rodrigues R, et al. Low bone mass prevalence, therapy type, and clinical risk factors in an HIV-infected Brazilian population. J Clin Densitom. 2011 Oct-Dec;14(4):434-9.

6. Wang MWH, Wei S, Faccio R, Takeshita S, Tebas P, Powderly WG, et al. The HIV protease inhibitor ritonavir blocks osteoclastogenesis and function by impairing RANKL-induced signaling. J Clin Invest. 2004 Jul;114(2):206-13.

7. Dolan SE, Carpenter S, Grinspoon S. Effects of weight, body composition, and testosterone on bone mineral density in HIV-Infected women. J Acquir Immune Defic Syndr. 2007 Jun 1;45(2):161-7.

8. Thomas J, Doherty SM. HIV infection - a risk factor for osteoporosis. J Acquir Immune Defic Syndr. 2003 Jul 1;33(3):28191.

9. Montessori V, Press N, Harris M, Akagi L, Montaner JS. Adverse effects of antirretroviral therapy for HIV infection. CMAJ. 2004 Jan;170(2):229-38.

10. Dagistan S, Bilge OM. Comparison of antegonial index, mental index, panoramic mandibular index and mandibular cortical index values in the panoramic radiographs of normal males and male patients with osteoporosis. Dentomaxillofac Radiol. 2010 Jul;39(5):290-4.

11. Passos JS, Gomes Filho IS, Sarmento VA, Sampaio DS, Gonçalves FP, Coelho JM, et al. Women with low bone mineral density and dental panoramic radiography. Menopause. 2012 Jun;19(6):704-9.

12. Taguchi A, Tsuda M, Ohtsuka M, Kodama I, Sanada M, Nakamoto T, et al. Use of dental panoramic radiographs in identifying younger postmenopausal women with osteoporosis. Osteoporos Int. 2006 Dec;17(3):387-94.

13. Geraets WG, Verheij JG, van der Stelt PF, Horner K; Lindh C; Nicopoulou-Karayianni K, et al. Prediction of bone mineral density with dental radiographs. Bone. 2007 May;40(5):121721.

14. Chalazonitis AN, Koumarianos D, Tzovara J, Chronopoulos P. How to optimize radiological images captured from digital cameras, using the Adobe Photoshop 6.0 program. J Digit Imaging 2003 Jun;16(2):216-29.

15. Taguchi A, Ohtsuka M, Nakamoto T, Naito K, Tsuda M, Kudo Y, et al. Identification of postmenopausal women at risk of osteoporosis by trained general dental practitioners using panoramic radiographs. Dentomaxillofac Radiol. 2007 Mar;36(3):149-54.

16. Klemetti E, Kolmakov S, Kröger H. Pantomography in assessment of the osteoporosis risk group. Scand J Dent Res. 1994 Feb;102(1):68-72.

17. Taguchi A, Suei Y, Ohtsuka M, Otani K, Tanimoto K, Ohtaki $\mathrm{M}$. Usefulness of panoramic radiography in the diagnosis of postmenopausal osteoporosis in women. Width and morphology of inferior cortex of the mandible. Dentomaxillofac Radiol. 1996 Nov;25(5):263-7.

18. Dutra V, Yang J, Devlin H, Susin C. Mandibular bone remodeling in adults: evaluating on panoramic radiographs. Dentomaxillofac Radiol. 2004 Sep;33(5):323-8.

19. Benson BW, Prihoda TJ, Glass BJ. Variations in adult cortical bone mass as measured by a panoramic mandibular index. Oral Surg Oral Med Oral Pathol. 1991 Mar;71(3):349-56.

20. Kojic EM, Wang CC, Cu-Uvin S. HIV and menopause: a review. J Womens Health (Larchmt). 2007 Dec;16(10):1402-11.

21. Miller SA, Santoro N, Lo Y, Howard AA, Arnsten JH, FlorisMoore M, et al. Menopause symptoms in HIV-infected and drug-using women. Menopause. 2005 May-Jun;12(3):348-56.

22. Conde DM, Silva ET, Amaral WN, Finotti MF, Ferreira RG, Costa-Paiva L, et al. HIV, reproductive aging, and health implications in women: a literature review. Menopause. 2009 Jan-Feb;16(1):199-213.

23. Arnsten JH, Freeman R, Howard AA, Floris-Moore M, Santoro N, Schoenbaum EE. HIV infection and bone mineral density in middle-aged women. Clin Infect Dis. 2006 Apr 1;42(7):1014-20.

24. Fausto A, Bongiovanni M, Cicconi P, Menicagli L, Ligabò EV, Melzi S, et al. Potential predictive factors of osteoporosis in HIV-positive subjects. Bone. 2006 Jun;38(6):893-7.

25. Schambelan M, Benson CA, Carr A, Currier JS, Dubé MP, Gerber JG, et al. Management of metabolic complications associated with antirretroviral therapy for HIV-1 infection: recommendations of an international Aids society- USA panel. J Acquir Immune Defic Syndr. 2002 Nov 1;31(3):257-75.

26. Grund B, Peng G, Gibert CL, Hoy JF, Isaksson RL, Shlay JC, et al. Continuous antiretroviral therapy decreases bone mineral density. AIDS. 2009 Jul 31;23(12):1519-29.

27. Carr A, Hoy J. Low bone mineral density with tenofovir: does statistically significant mean clinically significant? Clin Infect Dis. 2010 Oct;51(8):973-5.

28. Rivas P, Górgolas M, García-Delgado R, Díaz-Curiel M, Govenechea A, Fernández-Guerrero ML. Evolution of bone mineral density in AIDS patients on treatment with zidovudine/ lamivudine plus abacavir or lopinavir/ritonavir. HIV Med. 2008 Feb;9(2):89-95.

29. Leite AF, Figueiredo PT, Guia CM, Melo NS, de Paula AP. Correlations between seven panoramic radiomorphometric índices and bone mineral density in postmenopausal women. Oral Surg Oral Med Oral Pathol Oral Radiol Endod. 2010 Mar;109(3):449-56.

30. Celenk C, Celenk P. Relationship of mandibular and cervical vertebral bone density using computed tomography. Dentomaxillofac Radiol. 2008 Jan;37(1):47-51. 